Parisitism of Hipponamia convergens. -On page 188 of the present volume of Psyche is an article by C. M. Weed and C. A. Hart in which is recorded their observations on the lady-beetle parasite (Perilitus americanus), an account of which was first given by Dr. C. V. Riley on page ror of volume $r$ of Insect life. All of the observations referred to in these articles speak of this parasite as attacking Megilla maculata except in one instance where Dr. Riley speaks of one specimen of $C$. 9-notata which was probably attacked by the same parasite. I wish to add $H$. convergens to the list, a single specimen of which I took on the $I 7$ th of August, 1889 , from a corn leaf where it was standing dead, over a little brown cocoon exactly as M. maculata is represented in Insect life. The parasite had escaped when the discovery was made.

This has been the most common ladybeetle at Ames, Iowa, the past summer wherever plant lice have been abundant.

\section{P. Gillette.}

Emphytus cinctus in America. - Late in the autumn of 1887 I found a large number of sawfly larvae, not before observed, on the under side of leaves of several species of rose bushes at the Arnold Arboretum and one or two other places in the vicinity of Boston. Early in 1888 two or three sawflies emerged from some larvae which had been kept in confinement from the previous autumn, but being forgotten little more than the wings were found. The larvae were again plentiful in 1888 and about $1_{5}$ Sept. I succeeded in rassing several perfect sawflies. These I was unable to determine or to get determined for me. The past summer I raised one or two more from larvae and captured a number of the sawflies as they were flying about rose bushes. Unable to find any American species to correspond with these, I referred to descriptions of European species and have been able to identify $m y$ specimens beyond doubt as Emphytus cinctus L. a spe- cies common in England and on the Continent. These American specimens also agree in all particulars with European specimens in the Museum of comparative zoology at Cambridge.

F. G. Fack.

Power of Vision in Vespidae. - One day in the middle of July, while confined by illness to my tent on the summit of the Roan Mountains, Col., I was able to watch at leisure the operations of a couple of wasps which had entered the tent and were searching for flies along the tent roof. The tent was an ordinary wall tent, Io ft. $X \mathrm{r}_{2} \mathrm{ft}$., where, lying upon his back, the observer might readily follow all the movements of these creatures. There were also in the tent perhaps a dozen or twenty flies, mostly collected near the ridge pole, especially, when not in flight, alighting upon a rope which stretched from one of the upright poles supporting the tent to the other,just below the ridge pole. The wasps were in incessant motion, and in the course of one morning were seen to capture only three or four flies, the flies usually being able to dodge them whenever an attack upon them was made. I was unable to see that a wasp accelerated its motion in the least when approaching the flies or directed its flight immediately upon them until within two or three inches of its intended victim; and as it often passed one by at no greater distance than this without any attempt at capture, the impression was strong that the wasp's distinct vision while in flight did not exceed this distance. But what was most surprising was the great number of mistakes made by the wasps. Every slight stain or defect in the canvas or minute shadow upon it was repeatedly attacked by the wasps as if they supposed it to be a suitable object for food. There seemed to be no power on their part of distinguishing between a spot of color upon the canvas having no elevation whatever and an object or body resting upon it. Several times the shadow made bv a fly 

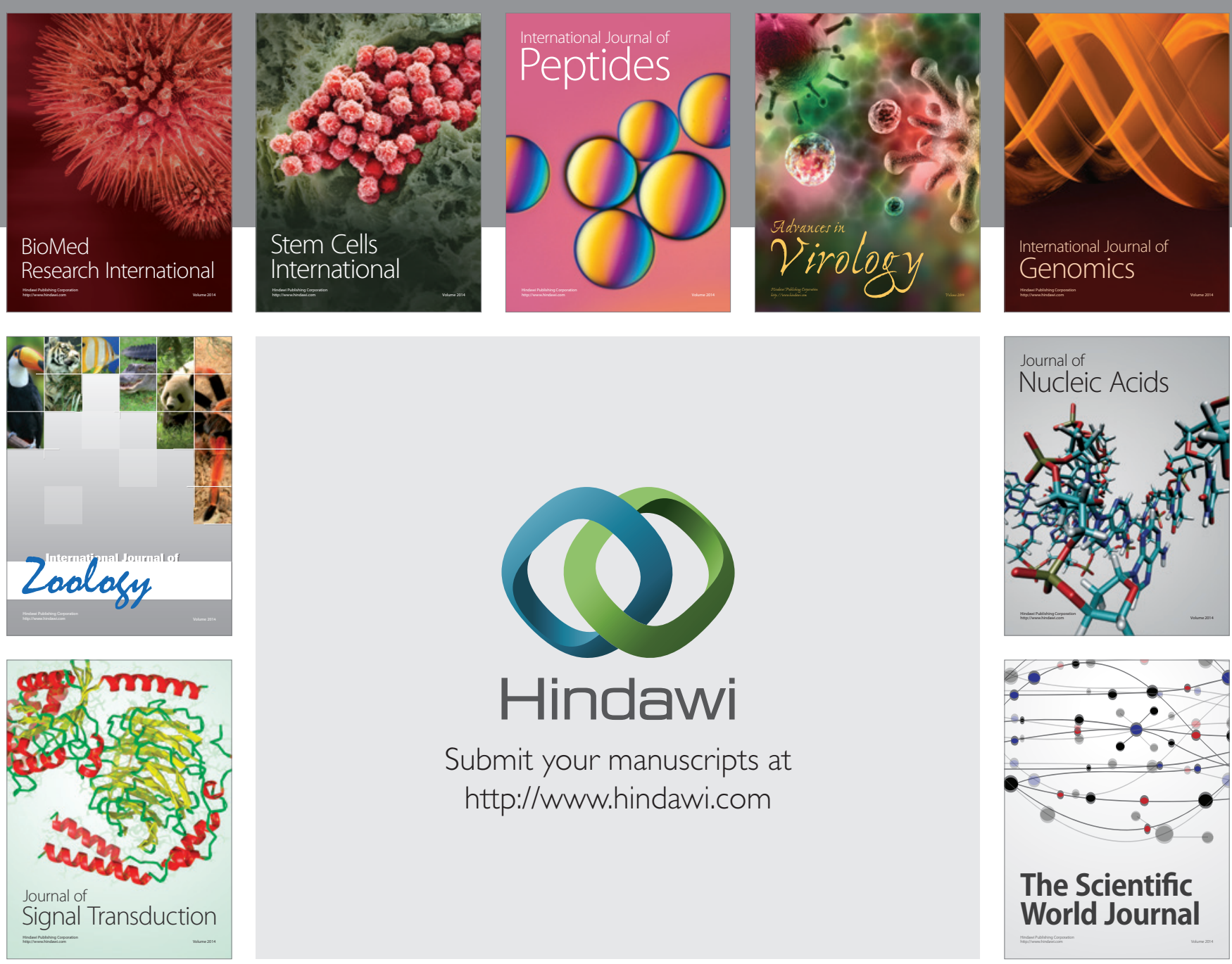

Submit your manuscripts at

http://www.hindawi.com
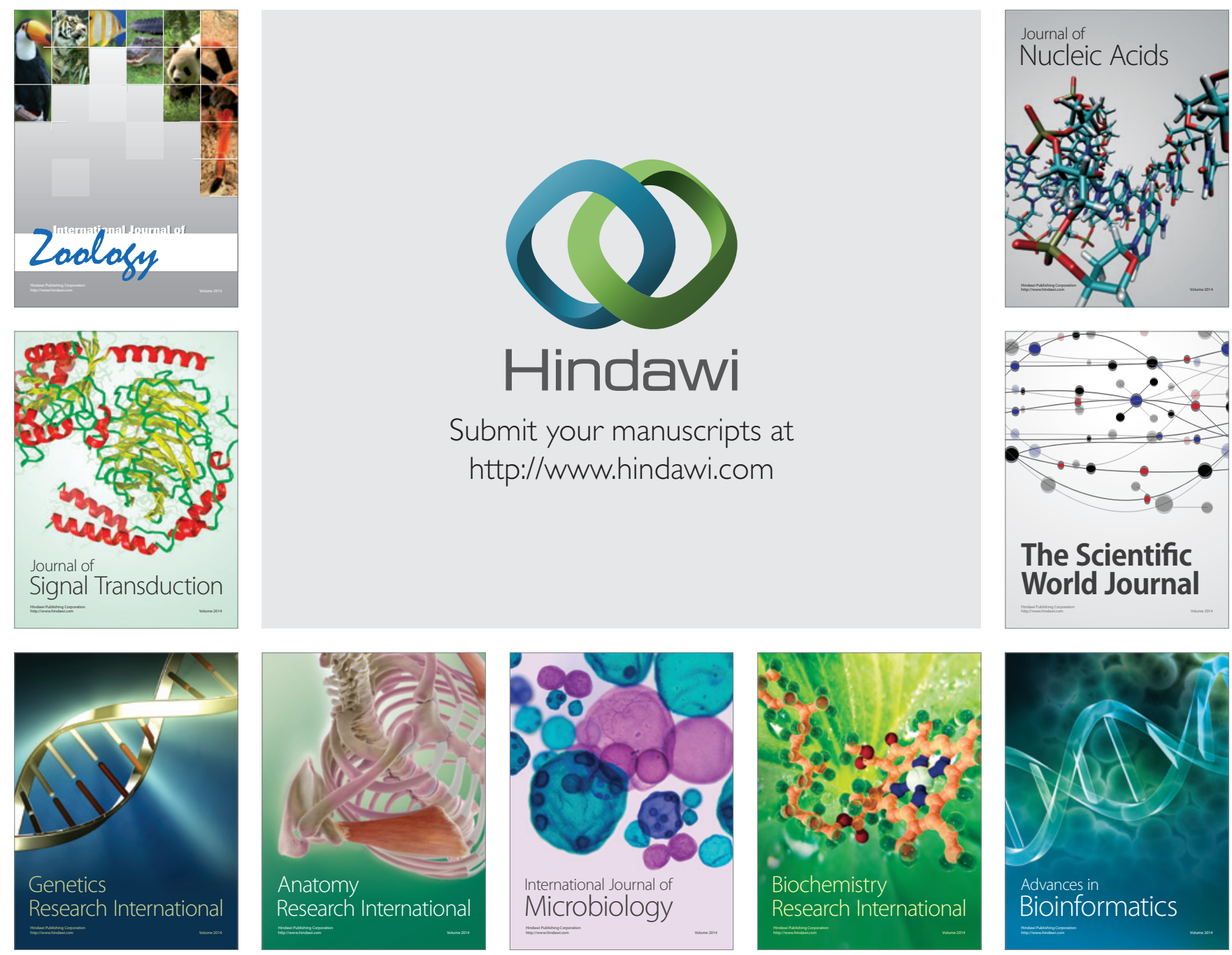

The Scientific World Journal
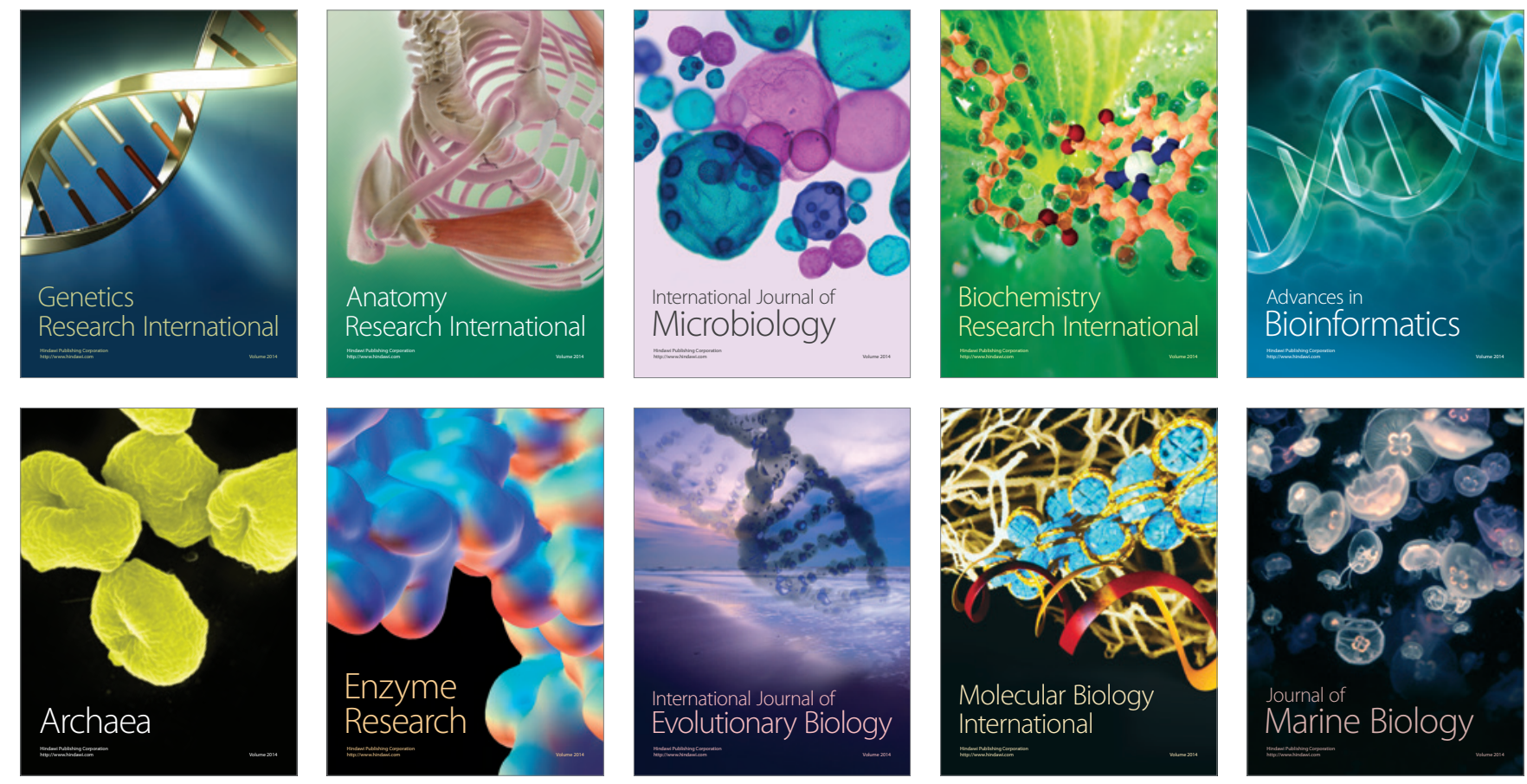